\title{
Research on Garden Landscape Planning and Construction in New Rural Construction of Jiaodong Region
}

\author{
Di Song \\ Yantai Nanshan College \\ Yantai, China
}

\begin{abstract}
With the rapid development of economy in Jiaodong, the new rural environmental construction is developing at an unprecedented speed. The rural landscape and garden planning and construction are included in the overall work of new rural construction. How to inherit and carry forward the traditional local culture, and to create modern rural landscape garden with rural characteristics are new challenges in garden and landscape planning and construction. This paper analyzes the present situation and problems of rural landscape in Jiaodong, expounds the features and functional requirements of rural ecological garden and landscape, discusses garden greening planning, garden greening and landscape construction technologies, the coordination of rural landscape structure and ecological functions, and the combination of rural courtyard garden greening and courtyard economy, regional characteristics of rural landscape and garden construction.
\end{abstract}

Keywords-new rural construction; rural garden landscape; Jiaodong region

\section{INTRODUCTION}

In the last two years, the construction of rural towns in Jiaodong region is developing at an unprecedented speed. The whole plan of the new rural construction is in full swing, and the rural environmental regulation is the important content of the new rural construction, and the construction of rural garden landscape is also listed in the overall work of new rural construction. But at present, in Jiaodong region and even in China, the understanding of garden landscape is only limited to the city, and there is no relevant standard and technical guidance for the construction of rural garden landscape. Most of the villages and towns are confined to road greening and residential courtyard greening. The green level is monotonous, and the rate of green space is low. And most greening is constructed by our ancestors. Our greening mainly relies on primary old trees and nearby forest land and cultivated land. The cultivated lands cover soil of rural towns. For greening in residential area, someone think tree and grass greening are enough. But it lacks overall planning, and cannot play a very good role in ecological protection. Some copy the greening model of city, with high investment, and make it urbanized, so that the long-accumulated and deposited history and culture and pattern of the old country disappear. Such greening is lack of rural characteristics and personality. Therefore, how to inherit and promote traditional culture of Jiaodong region and create a modern rural landscape garden in a non-urban development model with Jiaodong characteristics is a new challenge to the garden landscape planning and construction.

\section{The PRESENT SituATION AND PROBLEMS OF RURAL LANDSCAPE IN JIAODONG REGION}

\section{A. Lack of Reasonable Overall Planning and With Disordered Landscape Pattern}

At present, although some villages have prepared an overall village planning, but the level of overall planning is low. Main manifestations are: overall planning is mostly stereotyped. Some places adopt the layout mode of the urban residential area, lacking of rural environment features; some are of single forms, with large areas of determinant arrangement or pictographic composition arrangement, and lacking freedom and amiable rural life atmosphere and characteristics. Many small rural towns are with a disordered and unreasonable planning. The urban internal functions of residence, industry and business are not clear. The infrastructures of rural towns are poor, with imperfect road system. It is not conducive to transport and reasonable use of land, resulting in serious landscape fragmentation.

\section{B. Stressing Use Function of Building, but Despising the Function of Artistry and Lacking Personality}

In Shandong, folk customs are simple. They insist on the economic and practical design guideline, and give consideration to beauty wherever possible for a long term. Most rural buildings copy the patterns of urban residence and villa. Under the economic restriction in rural areas, they pay too much emphasis on functionality and utilization of building, and pursue low-cost living space construction with strong applicability. The building of "matchbox style" became a representative in a period of time. It ignores the ornamental function and local characteristics and personality of building. Take the Longkou Economic Development Zone of Jiaodong Peninsula as an example. In recent years, this region has developed the real estate economy in a large scale. In a short period of five years, they have built a lot of 
residential districts and commercial districts. But viewing them overall, these buildings are same, with nothing new. Though there is new atmosphere after reform and opening up, our construction lacks personality, which makes people fatigue in aesthetics.

\section{Separating from Rural Production and Life}

At present, the majority of villages are not high in rural agricultural modernization. Most villages still follow the traditional mode of agricultural production, so that function requirements for rural residence are completely different from that of urban residence. Therefore, it is very necessary to consider residence, storage yard, sunning ground, warehouse and pre-production handling room in the overall planning of new countryside. However, at present, the new rural construction excessively copies the mode of city, so it is separated from agricultural production and farmers' unique way of life.

\section{The Destroyed State of Rural Living Space}

In the lack of overall planning, the layout of rural building is at discretion. The layout of industrial and agricultural production is lack of co-ordination arrangement. People frequently change land use types, resulting in the disappearance of river, farmland, forests and other natural plates. The pastoral scenery is blocked by high-rise buildings. Old streets and small alleys hidden in village and little rivers before old houses, old camphor trees in the courtyard are difficult to see. Interesting and colorful life space is threatened, and the liberal life and large space in village are destroyed.

\section{E. Natural and Semi-Natural Landscape Degradation and Ecological Imbalance}

Trees, rivers (streams), ponds and natural vegetation are the inherent characteristics of countryside. However, the large scale of rural development and construction are seldom considered the natural elements of the rural areas. Instead, deforestation and land clearing destroy primary forests. Forests disappear, and birds and other small animals disappear. The varieties of agricultural production become single. Farmers use excessive amount of herbicides and pesticides, resulting in the reduction of biodiversity in the countryside. The domestic wastewater and industrial wastewater have polluted source of water. The industrial production has polluted the air. Unreadable development and construction lead to soil erosion. All these not only make the countryside lose the pastoral landscape features, but also have caused serious damage to the ecological environment.

\section{F. The Ecological Problems in Landscape}

The rural construction without a scientific overall planning makes the rural landscape space layout unreasonable, lacking necessary landscape connectivity. The landscape fragmentation problem and ecological problems are serious.

The excessively fast development leads to the lack of cultural connotation in its construction. Many iconic lives of the generation after $80 \mathrm{~s}$ has disappeared or been replaced by boring construction of "matchbox style". Aiming at this problem, we must understand the rural landscape culture profoundly in order to solve the contradiction between development and tradition.

\section{THE RURAL LANDSCAPE STRUCTURE AND GARDEN LANDSCAPE FEATURES}

\section{A. The Rural Landscape Structure}

Rural landscape is a kind of landscape type with specific landscape behavior, form and connotation. The settlement pattern includes scattered farmhouse and towns that can provide production and life service. The representative areas are in extensive form of land utilization, thin in population density, with obvious rural characteristics. The key points of rural landscape, different from other landscape, are its agricultural production landscape and extensive land use landscape and unique rural culture and life. Secondly, the rural landscape is a special type of rural resource, which is pleasant to people. It is also a comprehensive resource that can be developed and utilized.

From the view of landscape composition, the rural landscape is a landscape environment complex composed of rural settlement landscape, economic landscape, cultural landscape and natural environment landscape. From the view of landscape features, it is a complex of human landscape and natural landscape, mainly oriented by natural environment. From the view of its difference from other landscapes, it is an agricultural production landscape and extensive land use landscape, rural field culture and life. The rural landscape are composed of three parts, including the rural settlement landscape, rural farmland landscape with field work behavior, and rural cultural landscape with rural life behavior.

1) Rural settlement landscape is a multifunctional space activities network composed by streets and lanes, river system and other material elements. It is a place to hold people's living life, neighborhood contacts and recreational activities, and it is the core of the rural landscape. Due to geographical differences in China, the natural geographical environment is complicated and the variation is large, which brings about the differences of man-earth relationship and the regional culture, and the structure and form differences of the rural settlement in China.

2) The rural farmland landscape is the result of people's long-term nature transformation in order to meet the material needs, and the form performance of production activities. For example, there is a large area of aquaculture, cornfield, orchard and other in Jiaodong Peninsula. The seasonal changes of landscape are obvious. It is an essential part of rural landscape and important environmental resource of rural settlements.

3) The rural culture is the soul of the rural landscape. It integrates into the rural settlement, economy, society and other parts in a tangible or intangible way, forming a unique regional culture. It is an attractive resource in the rural landscape, including the culture of settlement in the 
settlement building, the farming culture and the folk culture in agricultural production.

\section{B. The Characteristics of Rural Garden Landscape Construction}

1) The coordination of rural garden landscape and rural earth landscape: Countryside is an open space. Mountains and rivers, seasonal appearance, specific landforms, and farmland layout in countryside constitute the framework of the rural landscape. In landscape construction, we should make full use of earth landscape resource, coordinate garden landscape and earth landscape to realize afforestation of land and highlight features of countryside. The rural human settlement environment is a landscape environment complex with rural settlement landscape as core, which is based on the earth landscape. In the planning and design of rural landscape, we should protect the natural landscape resources, forests, lakes, grasslands, marshes, and maintain natural landscape processes and functions. At the same time, we should make landscape design based on the natural ecological system and ecological process, so as to reduce investment and form an optimal landscape and achieve harmony between biology and environment.

2) The agricultural production is the basic function of village in order to meet the rural economic conditions and functions and provide agricultural products for city. The productive ecological garden is the main type of rural landscape. For this purpose, we should consider rural economic conditions and functions in the selection of plant species and materials, expression approach of landscape function, and cost of landscape construction.

\section{THE STRATEGIES FOR NEW RURAL LANDSCAPE CONSTRUCTION}

\section{A. Taking Ecological Garden as Characteristic in Rural Garden Landscape Construction}

Production, environmental protection, and leisure entertainment are main functional requirements in rural landscape construction. There are plentiful landscape elements. The spatial heterogeneity is large. The farmland production and architectural layout are not structured. These are basic rural landscape features, which determine the huge differences among rural garden landscape construction, urban garden planning and construction. The ecological garden takes plants as basic materials, and puts ecological principle, ecological functions, and ecological benefits in an important position in order to establish a reasonable ecological system. The core is to improve the level of human health and cultural quality. Its construction principle is to produce more biological products and provide more social welfare services with less investment.

\section{B. The Key Technologies in the Rural Garden Landscape Construction}

The paper has discussed the key technologies of rural landscape construction from many views, such as rural natural geography, climate condition, residential layout, production and life style, and functional requirements in Jiaodong region. The technologies include residential environment space optimization and function coordination technology, tree species selection technologies for rural greening, rural water resource utilization and ecological water landscape construction technology, rural old tree and woods protection technology and etc.

\section{The Combination Of Rural Courtyard Garden Landscape And Courtyard Economy}

To develop garden flowers, fruit tree and economic crops around houses can increase farmers' income and beautify home environment. The rural garden landscape construction can not only take full consideration of rural building environment but also make full use of courtyard space resource, and thus realize the function of rural garden landscape and develop courtyard economy.

\section{The Coordination Of Rural Landscape Structure And Ecological Function}

From the view of landscape ecology, the rural landscape is a mosaic of buildings, rivers, farmlands, forests, roads, ponds, pasture and orchards. The reasonableness of structure, composition and space heterogeneity is an important factor influencing the realization of rural ecological function. In the construction of rural garden landscape, we should fully consider structure of rural landscape, features, and their relationship with rural function in order to improve the rural landscape layout and rural ecological function.

\section{E. Making Full Use of the Existing Landscape Resources in Rural Areas}

Agriculture and animal husbandry production are main rural production contents. In the production, orchards, cornfields, garden nurseries, aquaculture, and so on are important landscape elements and valuable landscape resources. Thus, we should make full use of rural characteristics in the construction and planning of new rural landscape, use local materials and organically combine the artificial landscape and the natural landscape.

\section{CONCLUSION}

With the promotion of the new rural construction, Jiaodong region as a blue area of Shandong Peninsula, its new rural landscape planning is increasingly concerned. As an open space, specific landforms and natural vegetation are basic features of countryside. The basic function of countryside is agricultural production, so the nature, economy and functions of countryside determine the huge difference of rural garden landscape construction from urban garden landscape construction. We should fully consider rural features in the construction of rural landscape. On the premise of protecting the integrity of rural landscape and rural cultural characteristics, we should coordinate the relationship between landscape resource development and environment protection, and thus create an ecologically balanced and beautiful rural environment. 


\section{REFERENCES}

[1] Liu Liming, Yang Lin, Li Zhenpeng, Research on Landscape Ecological Problems and Countermeasures in the Process of Rural Urbanization in China. Ecological Environment, 2006, 15 (1): 202206.

[2] Guo Jiayou. Problems and Countermeasures of Landscape Construction in Small Towns. Small Towns Construction, 2004 (9): 51-52.

[3] Wang Yuncai, Liu Binyi. Rural Landscape and Rural Landscape Planning in China. Chinese Garden, 2003 (1).

[4] Yang Maolin. The Connotation and its Research Progress of Cultural Landscape. 2000, 19 (1): 70-79. 